\title{
Quantitative trait locus analysis of hatch timing, weight, length and growth rate in coho salmon, Oncorhynchus kisutch
}

\author{
EK McClelland and KA Naish \\ School of Aquatic and Fishery Sciences, University of Washington, Seattle, WA, USA
}

\begin{abstract}
In quantitative genetics, multivariate statistical approaches are increasingly used to describe genetic correlations in natural populations, yet the exact genetic relationship between phenotype and genotype is often unknown. Quantitative trait locus (QTL) analyses can be used to describe the molecular basis of this relationship. In salmonids, growth and development are important fitness traits that are phenotypically correlated with each other and with other life-history traits, and an understanding of the molecular basis of these relationships is valuable for future evolutionary studies. Here, a QTL analysis using an outbred cross was initiated to determine the molecular basis of phenotypic correlations between such growth traits in coho salmon (Oncorhynchus kisutch), an important fish species distributed throughout the North Pacific Ocean. Fifty-three QTL for growth rate, length and weight at eight time periods were
\end{abstract}

Keywords: QTL; salmonids; growth; correlated traits

\section{Introduction}

Growth is an important fitness trait and is one factor affecting survival and fecundity across a wide range of taxa (Arendt, 1997). Growth rates may be correlated with other life-history traits including development rate and size at age (Cheverud et al., 1983; Mangel and Stamps, 2001). Whether such traits are positively or negatively correlated may be strongly influenced by environmental conditions (Lankford et al., 2001; Sundstrom et al., 2005; Gregersen et al., 2008). For example, both timing of development and large body size are often crucial for exploiting ephemeral resources or avoiding predation (Sundstrom et al., 2005; Biro et al., 2006). However, depending on resource availability, some species may adopt a strategy of allocating energy toward rapid development rather than toward achieving large body size. Other species may maximize efficiency of resource use rather than total resource utilization, resulting in a negative correlation between growth and development (Arendt, 1997).

Correspondence: Dr EK McClelland, School of Aquatic and Fishery Sciences, University of Washington, Box 355020, Seattle, WA 98195, USA.

E-mail: emcclell@u.washington.edu

Received 26 October 2009; revised 26 January 2010; accepted 1 February 2010; published online 17 March 2010 located on seven linkage groups (OKI03, OKI06, OKI18, OKI19, OKI23, OKI24 and an unnamed linkage group) or associated with five unlinked markers (Omm1159, Omm1367/ i, Omy325UoG, OmyRGT55TUF and OtsG422UCD). One QTL for hatch timing was associated with the marker, Omm1241. All QTL were of minor effect, explaining no more than $20 \%$ of the observed variation in phenotypic value. Several instances of colocalization of QTL weight, length and growth rate were observed, suggesting a genetic basis for phenotypic correlations observed between these traits. This study lays the foundation for future QTL mapping efforts, for detailed examinations of the genetic basis of phenotypic correlations between growth traits, and for exploring the adaptive significance of growth traits in natural populations. Heredity (2010) 105, 562-573; doi:10.1038/hdy.2010.22; published online 17 March 2010
Genetic correlations between traits have implications for the adaptation and evolution of a species. Evolutionary response is determined by phenotypic variation, by the strength and direction of selection, by the underlying genetic variation within a population and by the genetic covariance between traits (Falconer and Mackay, 1996). Genetic correlations limit the number of trait combinations that are advantageous and thus constrain the evolution of correlated phenotypes (McGuigan, 2006). Statistical quantitative techniques have often been used to examine the genetic variance and covariance of fitness traits (Lynch and Walsh, 1998). This type of analysis has been very illuminating but often fails to fully describe the genetic basis of complex traits and interactions between such traits. As a first step toward a more mechanistic understanding of these interactions, quantitative trait locus (QTL) analyses can be conducted to directly identify regions of the genome that might affect a suite of correlated traits.

QTL are regions of the genome that affect polygenic, continuously varying phenotypic traits. QTL are typically located in the genome by detecting the association of phenotypes with marker genotypes (Lynch and Walsh, 1998). In a recent review, Gardner and Latta (2007) found that correlated trait pairs tended to share a higher proportion of QTL than did uncorrelated traits. Therefore, mapping QTL underlying multiple traits within the same study can indicate if pleiotropic effects, where one 
locus affects more than one trait, explain genetic correlation between these traits (Lynch and Walsh, 1998). In addition, QTL analysis offers insight into the number of loci affecting a trait as well the relative distribution of the effects of such loci (Lynch and Walsh, 1998).

In salmonids, growth and development are important traits with fitness effects throughout their life history. Salmon are anadromous, rearing in freshwater for varying lengths of time (depending on species) before migrating to salt water where resources are more abundant and growth rates are high (Quinn, 2005). Large size and rapid growth are thought to be important during the freshwater phase, because salmon must compete with conspecifics for resources and escape from predation (Sundstrom et al., 2005). Salmon eggs are deposited in gravel of lakes and streambeds. Eggs hatch into alevin that rear in the gravel until they are able to begin exogenous feeding, at which time they emerge into the water column (Quinn, 2005). Rapidly developing embryos may have more access to resources, because they emerge from the gravel first and have more opportunity for feeding early in the season, resulting in larger size as fry (Beacham et al., 1988; Einum and Fleming, 2000). Greater size at the fry stage is positively correlated with freshwater overwintering survival (Quinn and Peterson, 1996). However, when predation is density dependent, early development and corresponding high growth rates as fry may increase an individual's exposure to predation risk and result in lower fitness (Sundstrom et al., 2005). In chinook salmon, juvenile growth rates are also positively correlated with the age and timing of smoltification, the physiological process of adapting to salt water (Beckman and Larsen, 1998), and with increased marine survival during the first winter at sea in coho salmon (Beamish et al., 2004). In contrast to these findings, a study in Atlantic salmon showed a negative correlation between pre-smolt size and post-smolt size, suggesting that the adaptive benefit of size varies across ages and species (Einum et al., 2002). Salmon spend a variable number of years in salt water and then return to freshwater to spawn (Quinn, 2005). Growth rates at critical periods in the 2 years before spawning may determine the age of maturation, and in particular, whether males will exhibit precious maturation or 'jacking' (Shearer and Swanson, 2000). In females, large size is correlated with fecundity, and large females tend to have both larger and more abundant eggs (Fleming and Gross, 1990; Campbell et al., 2006). Finally, egg size is positively correlated with the size of fry (Heath et al., 1999), which is important for survival as described above.

Recent QTL-based studies in salmonids have detected genetic correlations between growth traits and lifehistory traits, and have identified major and minor QTL for growth and development traits. In rainbow trout, QTL for length after emergence and time to hatching mapped to the same region of the genome, indicating possible pleiotropic effects on size and development rate (Robison et al., 2001; Nichols et al., 2008). Length has been phenotypically correlated with upper thermal tolerance, a physiological trait; two minor QTL for length and thermal tolerance mapped to the same region (Perry et al., 2005). These studies typically examine only a few traits at one or two time periods. This study will extend the work on salmonids by examining growth traits in coho salmon, Oncorhynchus kisutch, over a longer time period than previous studies, offering a more complete analysis of QTL from hatching up until the age coho typically undergo the physiological process of smoltification.

In this study, we use an outbred pedigree in coho salmon to map QTL underlying phenotypic traits related to growth and early development; namely, hatch timing, weight, length and growth rate. Outbred designs have the ability to expose more of the variation present in the originating populations because multiple QTL alleles can segregate in experimental families, thus potentially uncovering more evolutionarily important variation than inbred designs (Erickson et al., 2004). Response to selection on correlated traits in experiments using inbred lines has often differed from the predicted response given the correlations observed between the traits studied (Roff, 2007a). Use of populations that exhibit more of the genetic variation and genetic interactions present in natural populations may be useful in understanding the response to selection in the wild and the maintenance of long-term genetic variation (Roff, 2007a; Naish and Hard, 2008). Identification of genomic regions associated with growth traits in coho salmon is an important first step in locating genes of interest and in determining how genes may interact to affect evolution of fitness traits in this species.

\section{Methods}

\section{Experimental crosses and trait measurements}

An outbred pedigree was established using individuals from two populations of coho from Washington State, USA. Females were obtained from the Bingham Creek hatchery, which is located on a tributary to the Satsop River in southwest Washington. This hatchery takes wild broodstock into the hatchery each year. Juveniles are released into the wild annually and thus experience natural selection for a substantial portion of their lives. Males were provided from the Domsea broodstock farm located near Olympia, Washington. The Domsea broodstock has been selectively bred for large size and early maturation for over 15 generations (Myers et al., 2001a). These populations have previously been shown to differ at traits relating to growth rate, and size at alevin and juvenile life-history stages (McClelland et al., 2005).

Twenty F1 hybrid crosses were established in December 2005 by mating each male with two females. Fertilized eggs were incubated in Heath trays at a constant $10^{\circ} \mathrm{C}$. On day 30 after fertilization, 1000 eggs from two paternal half-sib families were transferred to 100 -well incubation boxes to minimize the influence of hatching enzyme on unhatched eggs (Robison et al., 1999). Half-sib families were selected by egg size; one female had relatively small eggs (average egg diameter was $7.14 \pm 0.08 \mathrm{~mm}$ ) and the other female had relatively large eggs (average egg diameter was $8.30 \pm 0.09 \mathrm{~mm}$ ). The program IncubWin (Jensen and Jensen, 1999) was used to estimate the start of hatching using water temperatures. Eggs were inspected every 6-8 h from the estimated start of hatching (38 days or 380.8 degreedays) until all eggs had hatched; no eggs hatched before the estimated start time. All embryos that hatched within 
Table 1 Approximate life-history stage, sampling date, sampling as days after fertilization and the trait measured for QTL analysis

\begin{tabular}{|c|c|c|c|}
\hline Life-history stage & Date & Days since fertilization & Measurements taken \\
\hline Fertilization & 06 January 2006 & 0 & \\
\hline Start hatch & 17 January 2006 & 42 & time to hatching \\
\hline End hatch & 22 January 2006 & 47 & \\
\hline Start exogenous feeding & 27 February 2006 & 83 & \\
\hline Juveniles (pre-smolt) & 07 July 2006 & 213 & weight, length \\
\hline Juveniles (pre-smolt) & 23 August 2006 & 260 & weight, length \\
\hline Juveniles (pre-smolt) & 06 October 2006 & 304 & weight, length \\
\hline Juveniles (pre-smolt) & 16 November 2006 & 346 & weight, length \\
\hline Juveniles (pre-smolt) & 05 January 2007 & 395 & weight, length \\
\hline Juveniles (pre-smolt) & 14 February 2007 & 435 & weight, length \\
\hline Juveniles (smolts) & 30 March 2007 & 479 & weight, length \\
\hline Juveniles (smolts) & 16 May 2007 & 526 & weight, length \\
\hline
\end{tabular}

Growth rates were calculated from the weight measurements taken at each sampling period.

a given 6-8 $\mathrm{h}$ interval were assigned to the same hatching group, removed from the incubator boxes and reared together in a different incubator. Once yolk absorption was complete (day 83 after fertilization), hatching groups were placed in $1 \times 1 \times 0.5 \mathrm{~m}$ nets arrayed within a single $4 \mathrm{~m}$ diameter broodstock tank. If hatching groups were large, fish were divided between several nets so that no net had more than 60 individuals. Throughout the course of the experiment, fry were reared at a constant $10^{\circ} \mathrm{C}$ and fed to satiation. When fry reached approximately $3 \mathrm{~g}$ on average, 308 fish, selected proportionally from the different hatching groups, were marked with PIT tags (Biomark Inc., Boise, ID, USA) for individual identification and fin clips were collected for DNA extraction. At this time all fish were placed into the same $4 \mathrm{~m}$ diameter tank. Although smoltification traits were not quantified, smolts were first noted on day 345 after fertilization (November 2006). Length and weight measurements were taken every 6 weeks through June 2007 when fish were approximately 18 months of age (Table 1). Measurements were taken relatively frequently to ensure that growth during key intervals (for example, during the spring before smoltification and fall following) were assessed. Growth rates were calculated as the average daily change in body weight between measurement dates. The half-sib family that was the progeny of the dam with the larger diameter eggs was selected for further analysis.

\section{Statistical methods}

The hatch-timing data were treated categorically rather than as a continuous variable because phenotypes were recorded as the time interval in which an individual hatched. These data were not normally distributed. Phenotypic correlations between all traits were tested using Spearman's nonparametric rank test. Spearman's rank test is more appropriate for categorical data and data with non-normal distributions but is also a robust method of analyzing normally distributed, continuous data. Use of the nonparametric test facilitated analyses and comparisons between all traits. $P$-values were corrected using the sequential Bonferroni method with $\alpha=0.05$ and $k=276$ (Rice, 1989). Because hatching groups were reared at slightly different densities, analysis of variance was used to determine whether there was an effect of hatching group on size at the different sampling periods according to the model:

$$
Y_{i j k}=\mu+\alpha_{j}+\beta_{k}+\alpha_{j} \beta_{k}+\varepsilon_{i j k}
$$

where $Y_{i j k}$ is the phenotype of the $i$ th individual (in this case, length or weight for a given period), $\mu$ the population mean, $\alpha_{j}$ the affect of the $j$ th hatching time, $\beta_{k}$ the random affect of the $k$ th net, $\alpha_{j} \beta_{k}$ the interaction between hatch time and net, and $\varepsilon_{i j k}$ the random error. This analysis of variance takes into account any potential rearing group effects when determining the effect of hatching group on length or weight at age. The trait rank of fish over the course of the experiment was tested using Friedman's rank test for $k$ paired samples. All statistical tests were implemented using SPSS v 14.0 (SPSS Inc., Chicago, IL, USA).

\section{Genotyping}

Phenotypic information for hatch timing and growth traits was available for 308 individuals. Sixty-six individuals were chosen for genotyping based on their hatch timing. Thirty-three individuals hatched during the earliest $10 \%$ of the trait distribution and 33 were in the latest $10 \%$. Use of individuals representing extreme trait values, termed selective genotyping, can increase the power to detect QTL (Darvasi and Soller, 1992; Lynch and Walsh, 1998). When multiple traits are analyzed it is difficult to find individuals that represent the extremes for each trait unless traits are highly correlated (Darvasi and Soller, 1992). The individuals selected for hatch timing represented the range of values seen in the other traits measured. Fin clips were taken for DNA samples. Total genomic DNA was extracted using a DNeasy kit (Qiagen, Valencia, CA, USA). Microsatellite markers were chosen from a previously generated linkage map (McClelland and Naish, 2008); markers were selected to represent all known linkage groups with at least three markers per group. A total of 142 markers were screened in the parents of the mapping family. Both parents were homozygous for 56 of these markers, an additional 13 markers amplified duplicated loci for which it was not possible to determine parental haplotypes, and 3 loci had null alleles. The 66 individuals selected for QTL mapping were genotyped at the 70 loci which emerged from the marker screening process (Supplimentary Materials). Microsatellites were amplified in $10 \mu \mathrm{l}$ reactions containing $30 \mathrm{ng}$ genomic DNA, $1 \times$ buffer $(10 \mathrm{mM}$ Tris- $\mathrm{HCl}$, $50 \mathrm{mM} \mathrm{KCl}, 0.1 \%$ Triton X-100), 1.0-2.5 mM MgCl $2,200 \mu \mathrm{M}$ 
each dNTP, 2 pmol each of forward and reverse primer and 0.5 units Taq (GeneChoice, Frederick, MD, USA). Thermal cycling conditions consisted of a 5 min denaturing step at $95^{\circ} \mathrm{C}$ followed by 12 cycles of $95^{\circ} \mathrm{C}$ for $45 \mathrm{~s}$, $60{ }^{\circ} \mathrm{C}$ stepping down in $0.5^{\circ} \mathrm{C}$ increments to a final temperature of $54{ }^{\circ} \mathrm{C}, 72{ }^{\circ} \mathrm{C}$ for $1 \mathrm{~min}$. The touchdown sequence was followed by 20 cycles of $95^{\circ} \mathrm{C}$ for $45 \mathrm{~s}$, $54{ }^{\circ} \mathrm{C}$ for $45 \mathrm{~s}$ and $72{ }^{\circ} \mathrm{C}$ for $1 \mathrm{~min}$ with a final extension step of $72{ }^{\circ} \mathrm{C}$ for $45 \mathrm{~min}$.

\section{Linkage analysis}

Salmonids can have large differences in recombination rates between the sexes so it is necessary to generate sexspecific linkage maps (Sakamoto et al., 2000). Linkage groups were determined using the program LINKMFEX v2.1 (Danzmann and Gharbi, 2001). Using this program, we performed pairwise comparisons between loci separately for the dam and sire, and the 66 mapping progeny at all 70 microsatellite loci. A log of odds score of 3.0 was set as the threshold for clustering markers into linkage groups. Marker order was established using MAPORD and distances between markers was calculated using MAPDIS (both available as part of the LINKMFEX package). MAPORD attempts map construction using both a linear method, which minimizes the recombination distance between neighboring markers, and a matrix approach, which considers distances between each pair of markers in turn (Danzmann and Gharbi, 2001). MAPDIS uses phase-corrected genotypic data to establish mapping distances for each linkage group; mapping distances are representative of recombination frequencies between loci (Danzmann and Gharbi, 2001). Graphical representations of linkage groups were created using MapChart (Biometris, Wageningen, Netherlands; Voorrips, 2002). Linkage group names were assigned after the convention described in a previously defined coho linkage map (McClelland and Naish, 2008).

\section{QTL analysis}

The statistical power to detect QTL by interval mapping without selective genotyping and a sample size of 66 was calculated using the method developed by $\mathrm{Hu}$ and $\mathrm{Xu}$ (2008) for a backcrossed design. The method assumes a 'worst case scenario' where the QTL is located in the middle of a marker interval rather than immediately adjacent to a marker. A test statistic, $\lambda$, is defined such that, if the QTL overlaps an informative marker, the statistic will follow an F-distribution with degrees of freedom 1 and $n$, where $n$ is the sample size and will follow a noncentral F-distribution when the QTL does not overlap an informative marker. The noncentrality parameter is defined as follows:

$$
\delta=n \sigma_{x}^{2} \frac{a^{2}}{\sigma^{2}}
$$

where $n$ is the sample size, $\sigma_{x}^{2}$ is the variance of the genotype distribution, $\alpha^{2}$ is the additive genetic effect and $\sigma_{x}^{2}$ is the estimated residual error. The $1-\alpha$ percentile of the F-distribution is calculated as: $\lambda_{1-\alpha}=\mathrm{F}^{-1}\left(\lambda_{1-\alpha} \mid 1, n\right.$, 0 ) where $\alpha$ is the Type I error. Type II error is then defined as $\beta=\mathrm{F}\left(\lambda_{1-\alpha} \mid 1, n, \delta\right)$ and statistical power as $\gamma=1-\beta$ (Hu and $\mathrm{Xu}, 2008)$. The power analysis was performed for QTL in both large $(25 \mathrm{cM})$ and small intervals $(5 \mathrm{cM})$ to determine the power to detect QTL, with $\alpha=0.05$, of three effect sizes: major effect (percent explained variation, PEV, of 0.25), nonmajor effect (PEV of 0.15) and small effect (PEV of 0.05).

QTL analyses were performed separately for male and female parents because markers and QTL in individuals used to create outbred crosses can be in different linkage phases (Lynch and Walsh, 1998). Before QTL analysis, phase-corrected data were generated for each mapping parent separately using the program GENOVECT (part of the LINKMFEX package).

QTL analysis was performed with MultiQTL v2.5 (MultiQTL Ltd., Haifa, Israel) using a simple interval model (Lander and Botstein, 1989). Interval mapping locates QTL between markers but does not account for the effect QTL in nearby intervals may have on markertrait associations. The single-trait and two-trait models were both used, however, as the results did not differ, only the single-trait analyses are discussed here. To account for the differences in linkage maps, we analyzed dam and sire components separately using a backcross model to examine association between phenotypes and the two alleles from a given parent. Thus, for the analysis using the female parent, the effect of alleles segregating in the female (Bingham) line is averaged over the male alleles. The hatch-timing data were analyzed using a selective genotyping model because genotyped fish fell into the upper and lower $10 \%$ of the hatch-timing distribution. Other data were analyzed with the default, or reduced, model, which assumes no variance or covariance effects and no epistasis. Data other than hatch timing were not analyzed with the selective genotyping options because individuals genotyped represented the range of phenotypes for length, weight and growth rate. Linked markers were analyzed by interval analysis using the reduced model assuming equal variances. Significance levels were estimated using the permutation test of Churchill and Doerge (1994) with 10000 permutations of the trait data with an experimentwise false detection rate of 0.01 . $P$-values less than 0.05 from the interval analysis permutation test were considered indicative of a significant QTL effect. Unlinked markers were analyzed using the marker option of MultiQTL and significance was determined by permutation testing as above. $P$-values for single-marker analyses are less conservative than for interval mapping $\left(\mathrm{O}^{\prime} \mathrm{Mal}-\right.$ ley et al., 2003) so $P$-values of 0.01 were considered indicative of significant QTL effect. QTL that explained more than $25 \%$ of the variance (PEV) in the trait value were considered to be major QTL (Bradshaw et al., 1998). The substitution effect $(|\mathrm{d}|)$, the phenotypic difference between progeny with alternate alleles, was also estimated. The substitution effect reflects the additive component of variance; it was not possible to estimate dominance or epistatic effects due to the depth of the pedigree and the constraints of the backcross model in MultiQTL.

\section{Results}

\section{Statistical analysis of phenotypic correlation between} traits

Hatching occurred over a $96 \mathrm{~h}$ time period. The distribution of hatch timings was skewed with $28 \%$ of fish hatched during the first hatching period (1008 to $1014 \mathrm{~h}$ 
after fertilization), 52\% of fish hatched over the course of the subsequent $12 \mathrm{~h}$ and $73 \%$ of fish had hatched by the end of the first $30 \mathrm{~h}$. Of the 276 pairwise comparisons for correlations between traits, 251 comparisons were found to be correlated (Spearman's rank test, $P<0.0001$, Bonferroni-adjusted $\alpha=0.002) ; 253$ comparisons were correlated before Bonferroni correction. Hatch timing was positively correlated with length and weight on day 213 after fertilization (Spearman's rank test, $P<0.0001$, Bonferroni-adjusted $\alpha=0.002$ ) but was not correlated with length, weight or growth rate on any other days $(P>0.01$, Bonferroni-adjusted $\alpha$ ranged from 0.003 to 0.050). Weights and lengths at each sampling date were correlated with both weights and lengths on all other sample dates (for each test $P<0.0001$, Bonferroniadjusted $\alpha=0.002)$. Growth rates on each sample date were also correlated with all other weights and lengths (for each test $P<0.0001$, Bonferroni-adjusted $\alpha=0.002$ ), with the exception of growth rates from day 260 to 304 and from day 302 to 346 after fertilization that were not correlated with weight or length on day 213 (Spearman's rank test, Bonferroni-adjusted $\alpha>0.05$ ). Nets in which fish were reared from hatching until day 213 held unequal numbers of individuals, ranging from 17 to 60 fish per net with a median of 51.5 fish per net. However, there was no effect of fish density on weight, length or growth rate $(P>0.05)$. Fish that hatched at 1026 and $1057 \mathrm{~h}$ (10260 and 10570 degree-hours, respectively) after fertilization consistently had greater weights, lengths and faster growth rates over all sampling time periods than did fish from other hatching groups (nested analysis of variance, $P<0.05$ ). Individual ranks for the traits did not change significantly over the time of the experiment (weight: $\chi_{r}^{2}=1001.9, \quad P<0.001$; length: $\chi_{r}^{2}=1791.9, P<0.001$; growth rate: $\left.\chi_{r}^{2}=1022.4, P<0.001\right)$.

\section{Genetic map}

Sixty microsatellites were informative for generating the female map whereas 50 were informative for the male map. Six markers amplified duplicated loci, although in three cases only one copy could be assigned to a linkage group; the other copy was unlinked. Duplicated loci are designated by /i or /ii after the locus name. In the female map, 41 markers assigned to 16 linkage groups and in the male map, 31 markers assigned to 9 groups. Nineteen loci remained unlinked in both maps. Of these 19 loci, 15 were mapped in the opposite sex or have been mapped previously (McClelland and Naish, 2008) so it was possible to assign them to linkage groups, although recombination distances between markers in the current map were not calculated. The female map coverage was $210.16 \mathrm{cM}$, whereas the male map coverage was $114.37 \mathrm{cM}$. The intervals between markers ranged from 0 to $21.5 \mathrm{cM}$ in length. Total coverage is approximately $50 \%$ of previously published maps for each sex (McClelland and Naish, 2008). Although marker order was consistent between the previously published map and that generated for the QTL mapping family, recombination differences often varied. The difference in recombination rates between the sexes is consistent with previous observations in coho (McClelland and Naish, 2008). The male map represents 9 linkage groups out of the 22 mapped in an earlier study; the female map in this study comprises 12 of the 30 linkage groups previously mapped (McClelland and Naish, 2008). However, eight of the unlinked markers in the female, and nine in the male, are found on some of the linkage groups defined by the earlier study.

\section{QTL analysis}

The power analysis indicated that there was good power for detection of QTL with a PEV of 0.25 particularly in intervals of $10 \mathrm{cM}$ or less: $\gamma=0.75$ of $22 \mathrm{cM}$ intervals, $\gamma \geqslant 0.81$ of $10 \mathrm{cM}$ intervals and less. Power to detect QTL of small effect $(\mathrm{PEV}=0.05)$ was quite low with $\gamma=0.21$ for $22 \mathrm{cM}$ intervals rising to $\gamma=0.24$ for $5 \mathrm{cM}$ intervals. QTL with PEV of 0.15 were intermediate with $\gamma=0.52$ for $22 \mathrm{cM}$ intervals and $\gamma=0.60$ for $5 \mathrm{~cm}$ intervals. In all cases, power increased with an increase in marker density.

QTL for growth rate, weight, length or time to hatching mapped to seven regions of the coho genome (Figure 1, Table 2); an additional seven QTL were associated with individual markers only (Table 2). Twenty-two QTL, which mapped to three linkage groups and to two unlinked markers, were detected using segregation information from the dam. Thirty-five QTL, which mapped to four linkage groups and to four unlinked markers, were detected using the sire data (Table 2). Three of the regions (Omm1295 to Omm1265; Omy1011UW to Omm1310/Omm1154; and Omy325UoG to Omm1309/Omm1367/ii) were associated with QTL for growth traits over the majority of sampling periods. Where markers or intervals were associated with fewer QTL, those QTL tend to be for traits on the same or proximate dates (Figure 1). For example, OKI24 contains QTL for length on day 479 after fertilization and for growth rate from day 479 to 526 .

Only one QTL for hatch timing was observed, associated with Omm1241 in the dam analysis (Table 2), and this marker was not associated with any other QTL. It is interesting to note that although most traits were phenotypically correlated, phenotypic correlation did not always correspond to shared QTL. It appears that $64.5 \%$ of pairwise phenotypic correlations correspond to colocalized QTL. None of the QTL for any of the traits was considered to be of major effect, although 30 explained between $10 \%$ and $20 \%$ of the variation for their respective traits $(0.10 \leqslant P E V \geqslant 0.20$; Table 2$)$.

\section{Discussion}

Here we report genomic locations of QTL in coho salmon for hatch timing and for weight, length and growth rate over sampling periods spanning 2 years. Three genomic regions contained multiple QTL spanning many sample dates, whereas other regions were associated only with QTL for traits at later ages (day 479 after fertilization and later). It is therefore possible that some of the same loci, or linked loci, affect growth traits across all life-stages whereas other loci are expressed only during certain time periods. QTL for length at multiple ages mapped to the same location on OKI03, OKI19 and OKI23, suggesting that there may be pleiotropic effects on length across ages. Similar results were seen for weight at age and growth rate across ages. QTL for weight, length and/or growth rate at the same age also mapped to the same intervals on several linkage groups (OKI03, OKI19, $\mathrm{OKI} 23, \mathrm{OKI} 24$ and the unnamed linkage group), suggesting loci may have pleiotropic effects across traits 
OKI23 (male)
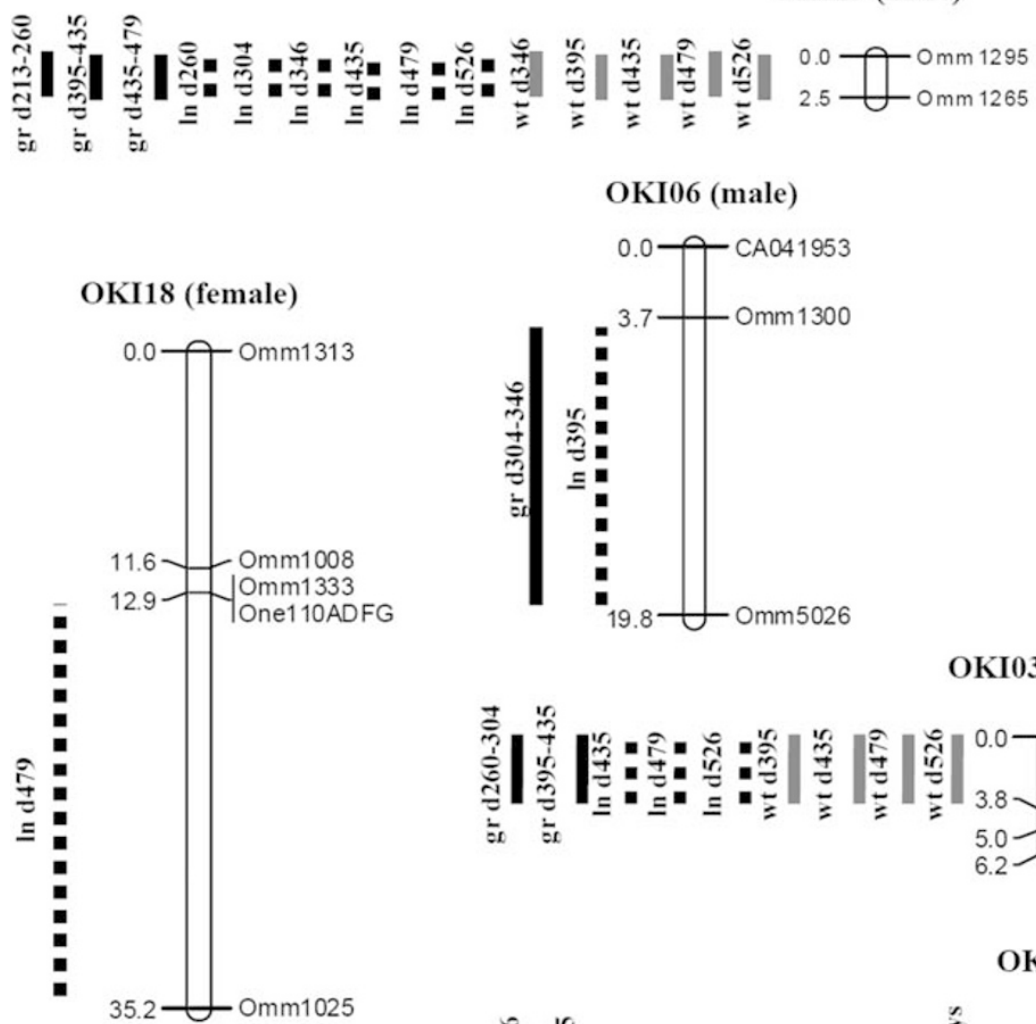

OKI03 (male)

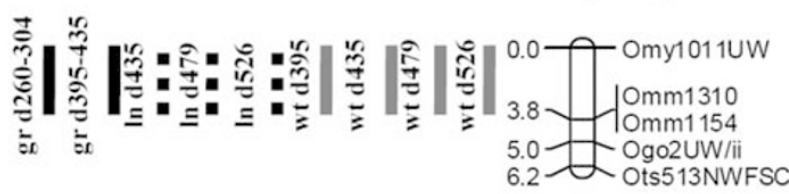

OKI19 (female)

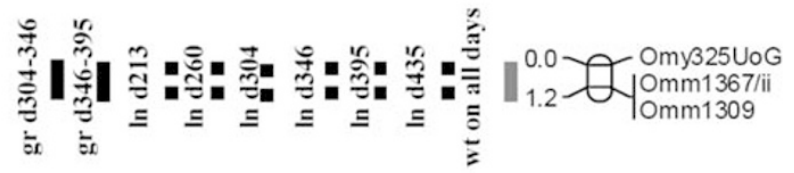

OKI24 (male)

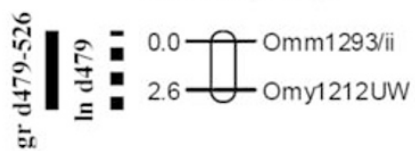

unkown (female)

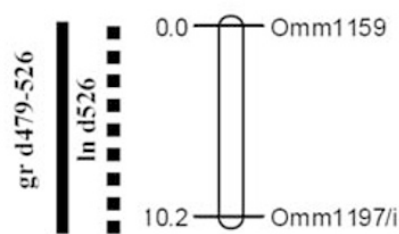

Figure 1 Linkage groups with quantitative trait locus (QTL). QTL for growth rate (gr), length (ln) and weight (wt) on various sampling days after fertilization that mapped to a marker interval on a linkage group. Linkage group names are as for previously published coho linkage groups (McClelland and Naish, 2008).

expressed at a specific age. All growth-related traits in this study were phenotypically correlated with each other and previous work on coho has shown high genetic correlations between weight and length at age ( $r$ ranges from 0.74 to 0.98; Myers et al., 2001b; Neira et al., 2004) and between weights at different ages ( $r$ ranges from 0.42 to 0.98; Hershberger et al., 1990; Myers et al., 2001b). QTL analyses are a first step in describing the genetic architecture underlying many of these genetic correlations.

All the QTL detected in this study were considered to be of minor effect because they each explain less than $25 \%$ of the variance of respective traits. The QTL for hatch timing had a particularly low PEV, explaining only $4.5 \%$ of the variation. Sample sizes below 300, as used here, typically have low power to identify QTL of small effect particularly at marker densities less than $15 \mathrm{~cm}$
(Erickson et al., 2004). Non-model organisms or outbred populations often have lower density linkage maps that increase the probability of failing to detect small effect QTL, if they exist (Lynch and Walsh, 1998). Selective genotyping can be used to increase the power to detect QTL while decreasing the number of individuals genotyped (Darvasi and Soller, 1992) as was performed for the hatch timing trait. However, this method can only be applied to one trait, except in the unlikely event that the trait distribution between individuals is maintained across all life-history stages (Darvasi, 1997). In this study, it is possible that QTL of small effect for growth related traits went undetected in this analysis. However, it is considerably less likely that QTL of major affect went undetected (probability of Type II error of 0.80 ). Some authors suggest that QTL of large effect are rare, whereas QTL of small effect are more commonly detected for 
Table 2 Linkage groups and markers to which QTL mapped for hatch timing, growth rates, length and weight at different days (d) after fertilization

\begin{tabular}{|c|c|c|c|c|c|c|c|c|c|}
\hline Trait & Linkage group & Marker & Source & $L O D$ & Effect, $m$ & $\begin{array}{l}\text { Substitution } \\
\text { effect, }|d|\end{array}$ & $\begin{array}{l}\text { Residual } \\
\text { variance }\end{array}$ & $\mathrm{P}$ & PEV \\
\hline hatch timing & (OKI14) & Omm1241 & dam & 1.16 & $1025 \mathrm{~h}$ & 9.27 & 21.44 & 0.009 & 0.045 \\
\hline \multirow[t]{2}{*}{ growth_rate_d213-260 } & OKI23 & \begin{tabular}{|l} 
Omm1295 \\
Omm1265
\end{tabular} & sire & 1.05 & $0.57 \mathrm{~g}$ & 0.37 & 0.66 & 0.021 & 0.073 \\
\hline & unknown & Omm1367i & sire & 1.52 & $0.62 \mathrm{~g}$ & 0.45 & 0.65 & 0.002 & 0.106 \\
\hline \multirow[t]{2}{*}{ growth_rate_d260-304 } & OKI03 & \begin{tabular}{|l} 
Omy1011UW \\
Omm1310/Omm1154
\end{tabular} & sire & 1.56 & $0.89 \mathrm{~g}$ & 0.86 & 0.87 & 0.011 & 0.196 \\
\hline & unknown & Omm1159 & sire & 1.45 & $0.96 \mathrm{~g}$ & 0.84 & 0.87 & 0.009 & 0.187 \\
\hline \multirow[t]{2}{*}{ growth_rate_d304-346 } & OKI19 & $\mid \begin{array}{l}\text { Omy325UoG } \\
\text { Omm1367/ii/Omm1309 }\end{array}$ & dam & 1.23 & $1.52 \mathrm{~g}$ & 1.61 & 1.73 & 0.012 & 0.161 \\
\hline & OKI06 & \begin{tabular}{|l|} 
Omm1300 \\
Omm5026
\end{tabular} & sire & 1.10 & $1.61 \mathrm{~g}$ & 1.48 & 1.74 & 0.042 & 0.152 \\
\hline growth_rate_d346-395 & OKI19 & \begin{tabular}{|l} 
Omy325 UoG \\
Omm1367/ii/Omm1309
\end{tabular} & dam & 1.23 & $1.45 \mathrm{~g}$ & 1.51 & 1.70 & 0.019 & 0.089 \\
\hline \multirow[t]{2}{*}{ growth_rate_d395-435 } & $\begin{array}{l}\text { (OKI17) } \\
\text { OKI03 }\end{array}$ & $\begin{array}{l}\text { OtsG422UCD } \\
\text { Omy1011UW } \\
\text { Omm1310/Omm1154 }\end{array}$ & $\begin{array}{l}\text { sire } \\
\text { sire }\end{array}$ & $\begin{array}{l}2.25 \\
1.11\end{array}$ & $\begin{array}{l}1.65 \mathrm{~g} \\
1.77 \mathrm{~g}\end{array}$ & $\begin{array}{l}0.93 \\
0.64\end{array}$ & $\begin{array}{l}1.03 \\
1.08\end{array}$ & $\begin{array}{l}0.002 \\
0.046\end{array}$ & $\begin{array}{l}0.167 \\
0.080\end{array}$ \\
\hline & OKI23 & $\mid \begin{array}{l}\text { Omm1295 } \\
\text { Omm1265 }\end{array}$ & sire & 1.57 & $1.74 \mathrm{~g}$ & 0.76 & 1.06 & 0.012 & 0.112 \\
\hline \multirow[t]{2}{*}{ growth_rate_d435-479 } & OKI23 & $\begin{array}{l}\text { Omm1295 } \\
\text { Omm1265 }\end{array}$ & sire & 1.00 & $2.36 \mathrm{~g}$ & 0.97 & 1.61 & 0.048 & 0.083 \\
\hline & unknown & Omm1159 & sire & 1.60 & $2.41 \mathrm{~g}$ & 1.21 & 1.58 & 0.008 & 0.128 \\
\hline \multirow[t]{2}{*}{ growth_rate_d479-526 } & OKI24 & \begin{tabular}{|l} 
Omm1293/ii \\
Omy1212UW
\end{tabular} & sire & 1.27 & $2.60 \mathrm{~g}$ & 1.19 & 1.78 & 0.025 & 0.101 \\
\hline & unknown & \begin{tabular}{|l} 
Omm1159 \\
Omm1197/i
\end{tabular} & dam & 1.16 & $2.75 \mathrm{~g}$ & 1.21 & 1.78 & 0.037 & 0.104 \\
\hline ln_d213 & OKI19 & \begin{tabular}{|l} 
Omy325UoG \\
Omm1309/Omm1367/ii
\end{tabular} & dam & 1.39 & $98.58 \mathrm{~mm}$ & 12.35 & 19.21 & 0.018 & 0.094 \\
\hline \multirow[t]{2}{*}{$\ln \_\mathrm{d} 260$} & OKI19 & \begin{tabular}{|l} 
Omy325UoG \\
Omm1309/Omm1367/ii
\end{tabular} & dam & 1.69 & $134.53 \mathrm{~mm}$ & 21.28 & 29.69 & 0.008 & 0.114 \\
\hline & OKI23 & \begin{tabular}{|l|} 
Omm1295 \\
Omm1265
\end{tabular} & sire & 1.06 & $132.20 \mathrm{~mm}$ & 17.11 & 30.36 & 0.042 & 0.074 \\
\hline \multirow[t]{2}{*}{ ln_d304 } & OKI19 & \begin{tabular}{|l} 
Omy325UoG \\
Omm1309/Omm1367/ii
\end{tabular} & dam & 1.01 & $167.05 \mathrm{~mm}$ & 25.50 & 46.88 & 0.043 & 0.069 \\
\hline & OKI23 & \begin{tabular}{|l|} 
Omm1295 \\
Omm1265
\end{tabular} & sire & 1.36 & $163.26 \mathrm{~mm}$ & 29.53 & 46.32 & 0.020 & 0.092 \\
\hline \multirow[t]{2}{*}{ ln_d346 } & OKI19 & \begin{tabular}{|l} 
Omy325UoG \\
Omm1309/Omm1367/ii
\end{tabular} & dam & 1.25 & $190.03 \mathrm{~mm}$ & 34.23 & 55.96 & 0.024 & 0.086 \\
\hline & OKI23 & \begin{tabular}{|l|} 
Omm1295 \\
Omm1265
\end{tabular} & sire & 1.24 & $185.82 \mathrm{~mm}$ & 34.25 & 55.98 & 0.027 & 0.085 \\
\hline \multirow[t]{2}{*}{ ln_d395 } & OKI06 & \begin{tabular}{|l|} 
Omm1300 \\
Omm5026
\end{tabular} & sire & 1.33 & $208.89 \mathrm{~mm}$ & 40.10 & 62.32 & 0.041 & 0.096 \\
\hline & OKI19 & \begin{tabular}{|l} 
Omy325UoG \\
Omm1309/Omm1367/ii
\end{tabular} & dam & 1.78 & $211.02 \mathrm{~mm}$ & 46.10 & 61.23 & 0.005 & 0.124 \\
\hline \multirow[t]{4}{*}{$\ln \_d 435$} & (OKI17) & OtsG422UCD & sire & 1.57 & $238.02 \mathrm{~mm}$ & 45.14 & 61.08 & 0.009 & 0.120 \\
\hline & OKI03 & \begin{tabular}{|l} 
Omy1011UW \\
Omm1310/Omm1154
\end{tabular} & sire & 1.53 & $245.22 \mathrm{~mm}$ & 42.86 & 61.18 & 0.017 & 0.109 \\
\hline & OKI19 & $\mid \begin{array}{l}\text { Omy325UoG } \\
\text { Omm1309/Omm1367/ii }\end{array}$ & dam & 1.36 & $245.31 \mathrm{~mm}$ & 40.56 & 61.57 & 0.018 & 0.098 \\
\hline & OKI23 & \begin{tabular}{|l|} 
Omm1295 \\
Omm1265
\end{tabular} & sire & 1.00 & $241.71 \mathrm{~mm}$ & 35.27 & 62.42 & 0.048 & 0.074 \\
\hline ln_d479 & OKI03 & \begin{tabular}{|l} 
Omy1011UW \\
Omm1310/Omm1154
\end{tabular} & sire & 1.04 & $277.05 \mathrm{~mm}$ & 38.32 & 63.93 & 0.047 & 0.082 \\
\hline
\end{tabular}


Table 2 Continued

\begin{tabular}{|c|c|c|c|c|c|c|c|c|c|}
\hline Trait & Linkage group & Marker & Source & $L O D$ & Effect, $m$ & $\begin{array}{l}\text { Substitution } \\
\text { effect, }|d|\end{array}$ & $\begin{array}{l}\text { Residual } \\
\text { variance }\end{array}$ & $\mathrm{P}$ & PEV \\
\hline & OKI18 & $\begin{array}{l}\text { One110ADFG/Omm1333 } \\
\text { Omm1025 }\end{array}$ & dam & 1.36 & $280.06 \mathrm{~mm}$ & 51.85 & 61.59 & 0.044 & 0.150 \\
\hline & OKI23 & $\begin{array}{l}\text { Omm1295 } \\
\text { Omm1265 }\end{array}$ & sire & 0.96 & $275.75 \mathrm{~mm}$ & 35.27 & 64.15 & 0.050 & 0.077 \\
\hline & OKI24 & $\begin{array}{l}\text { Omm1293/ii } \\
\text { Omy1212UW }\end{array}$ & sire & 0.32 & $276.22 \mathrm{~mm}$ & 43.17 & 63.17 & 0.021 & 0.105 \\
\hline \multirow[t]{3}{*}{ ln_d526 } & OKI03 & $\begin{array}{l}\text { Omy1011UW } \\
\text { Omm1310/Omm1154 }\end{array}$ & sire & 1.41 & $311.54 \mathrm{~mm}$ & 49.61 & 70.09 & 0.021 & 0.111 \\
\hline & OKI23 & $\begin{array}{l}\text { Omm1295 } \\
\text { Omm1265 }\end{array}$ & sire & 1.20 & $310.8 \mathrm{~mm}$ & 46.07 & 70.71 & 0.031 & 0.096 \\
\hline & unknown & $\begin{array}{l}\text { Omm1159 } \\
\text { Omm1197/i }\end{array}$ & dam & 1.40 & $316.06 \mathrm{~mm}$ & 49.87 & 70.11 & 0.022 & 0.112 \\
\hline wt_d213 & OKI19 & $\begin{array}{l}\text { Omy325UoG } \\
\text { Omm1309/Omm1367/ii }\end{array}$ & dam & 0.98 & $13.0 \mathrm{~g}$ & 3.88 & 7.24 & 0.048 & 0.067 \\
\hline wt_d260 & OKI19 & $\begin{array}{l}\text { Omy325UoG } \\
\text { Omm1309/Omm1367/ii }\end{array}$ & dam & 1.68 & $38.0 \mathrm{~g}$ & 17.47 & 24.43 & 0.007 & 0.113 \\
\hline wt_d304 & OKI19 & $\begin{array}{l}\text { Omy325UoG } \\
\text { Omm1309/Omm1367/ii }\end{array}$ & dam & 1.26 & $83.0 \mathrm{~g}$ & 53.82 & 61.49 & 0.025 & 0.161 \\
\hline \multirow[t]{3}{*}{ wt_d346 } & (OKI27) & OmyRGT55TUF & dam & 1.53 & $104.6 \mathrm{~g}$ & 66.97 & 95.52 & 0.010 & 0.109 \\
\hline & OKI19 & $\begin{array}{l}\text { Omy325UoG } \\
\text { Omm1309/Omm1367/ii }\end{array}$ & dam & 1.34 & $114.6 \mathrm{~g}$ & 63.53 & 99.95 & 0.017 & 0.092 \\
\hline & OKI23 & $\begin{array}{l}\text { Omm1295 } \\
\text { Omm1265 }\end{array}$ & sire & 1.22 & $107.0 \mathrm{~g}$ & 60.92 & 100.38 & 0.028 & 0.084 \\
\hline \multirow[t]{4}{*}{ wt_d395 } & OKI03 & $\begin{array}{l}\text { Omy1011UW } \\
\text { Omm1310/Omm1154 }\end{array}$ & sire & 1.12 & $151.3 \mathrm{~g}$ & 80.46 & 136.37 & 0.039 & 0.080 \\
\hline & (OKI19) & Omy325UoG & sire & 1.70 & $140.2 \mathrm{~g}$ & 98.25 & 133.47 & 0.005 & 0.119 \\
\hline & OKI19 & $\begin{array}{l}\text { Omy325UoG } \\
\text { Omm1309/Omm1367/ii }\end{array}$ & dam & 2.01 & $156.0 \mathrm{~g}$ & 106.23 & 131.93 & 0.004 & 0.139 \\
\hline & OKI23 & $\begin{array}{l}\text { Omm1295 } \\
\text { Omm1265 }\end{array}$ & sire & 1.02 & $148.8 \mathrm{~g}$ & 77.32 & 136.87 & 0.046 & 0.074 \\
\hline \multirow[t]{5}{*}{ wt_d435 } & OKI03 & $\begin{array}{l}\text { Omy1011UW } \\
\text { Omm1310/Omm1154 }\end{array}$ & sire & 1.31 & $224.9 \mathrm{~g}$ & 111.68 & 172.94 & 0.025 & 0.094 \\
\hline & (OKI17) & OtsG422UCD & sire & 1.57 & $208.2 \mathrm{~g}$ & 126.43 & 171.29 & 0.008 & 0.120 \\
\hline & OKI19 & $\begin{array}{l}\text { Omy325UoG } \\
\text { Omm1309/Omm1367/ii }\end{array}$ & dam & 1.64 & $228.8 \mathrm{~g}$ & 124.32 & 170.80 & 0.008 & 0.117 \\
\hline & (OKI27) & OmyRGT55TUF & dam & 1.60 & 216.50 & 123.71 & 165.90 & 0.008 & 0.122 \\
\hline & OKI23 & $\begin{array}{l}\text { Omm1295 } \\
\text { Omm1265 }\end{array}$ & sire & 1.33 & $221.2 \mathrm{~g}$ & 112.76 & 172.82 & 0.022 & 0.096 \\
\hline \multirow[t]{3}{*}{ wt_d479 } & OKI03 & $\begin{array}{l}\text { Omy1011UW } \\
\text { Omm1310/Omm1154 }\end{array}$ & sire & 1.36 & $318.0 \mathrm{~g}$ & 157.64 & 228.78 & 0.024 & 0.106 \\
\hline & OKI19 & $\begin{array}{l}\text { Omy325UoG } \\
\text { Omm1309/Omm1367/ii }\end{array}$ & dam & 1.12 & $326.0 \mathrm{~g}$ & 143.71 & 231.10 & 0.033 & 0.088 \\
\hline & OKI23 & $\begin{array}{l}\text { Omm1295 } \\
\text { Omm1265 }\end{array}$ & sire & 1.61 & $311.7 \mathrm{~g}$ & 171.45 & 226.45 & 0.011 & 0.125 \\
\hline \multirow[t]{4}{*}{ wt_d526 } & OKI03 & $\begin{array}{l}\text { Omy1011UW } \\
\text { Omm1310/Omm1154 }\end{array}$ & sire & 1.55 & $432.1 \mathrm{~g}$ & 216.71 & 290.58 & 0.014 & 0.122 \\
\hline & (OKI17) & OtsG422UCD & sire & 1.79 & $405.3 \mathrm{~g}$ & 240.17 & 287.75 & 0.004 & 0.148 \\
\hline & OKI19 & $\begin{array}{l}\text { Omy325UoG } \\
\text { Omm1309/Omm1367/ii }\end{array}$ & dam & 0.98 & $446.0 \mathrm{~g}$ & 174.78 & 297.61 & 0.046 & 0.079 \\
\hline & OKI23 & $\begin{array}{l}\text { Omm1295 } \\
\text { Omm1265 }\end{array}$ & sire & 1.24 & $429.2 \mathrm{~g}$ & 195.57 & 294.38 & 0.027 & 0.099 \\
\hline
\end{tabular}

Linkage groups given in parentheses indicate markers that were unlinked in the QTL cross but have been mapped previously in coho (McClelland and Naish, 2008). The parent in which the QTL was detected (source), max LOD score (LOD), effect (m) of the allele present on the trait, allelic substitution effect $(|\mathrm{d}|)$ at the QTL position, the residual (non-additive) variance, $P$-values for QTL $(\mathrm{P})$, and the proportion of variance explained by the QTL marker (PEV) are shown. Markers grouped by a vertical line indicate that the maximum LOD score for that QTL was detected in the interval between those markers. 
most traits (Lynch and Walsh, 1998; Mackay, 2004). Study results differ with respect to the number of major and minor QTL detected, and may relate both to the constraints of linkage map density as noted above and to breeding design (Roff, 2007b). In an inbred cross, for example, alleles of major effect can arise due to epistatic effects; these effects may be reduced in an outbred population in which a greater range of genetic backgrounds might be expected to occur (Roff, 2007b). Estimates of QTL effects in outbred populations are expected to be less precise than from inbred lines because QTL are expressed as genetic variances rather than means (Lynch and Walsh, 1998) and therefore some bias is likely with an outcross design. The range of effect sizes associated with QTL in this study are typical of other studies in outbred lines derived from natural populations of fishes (Peichel et al., 2001; Martyniuk et al., 2003; Rogers and Bernatchez, 2007). However, it would take further development of the coho linkage map to truly address the debate over the prevalence of small versus large effect QTL.

Although power to detect QTL is lower in outbred crosses than with inbred lines (Lynch and Walsh, 1998), there are many advantages to using an outbred design. Outbred designs are more likely to reveal the variation present in natural populations (Lynch and Walsh, 1998) and may thus be more relevant than inbred lines for determining the genetic basis of correlations in natural populations (Roff, 2007b). It has also been suggested that the colocalization of QTL for trait pairs is greater in natural populations (Gardner and Latta, 2007). In this study, QTL were mapped in the F1 generation; they therefore represent recombination events in the parents rather than in the F1 progeny. Because this study uses a single full-sib family for QTL mapping, the effect sizes of a QTL will incorporate the dominance interaction between parental alleles in the offspring (Lynch and Walsh, 1998). It is not immediately clear whether these dominance interactions will increase or decrease the apparent effect of the QTL on the marker in question (Lynch and Walsh, 1998). Additional studies mapping QTL in more families would be useful for elucidating the QTL effect across the population.

The Domsea broodstock are a domesticated line, and after several generations of selective breeding, inbreeding was estimated to be between $15 \%$ and 23\% (Myers et al., 2001a). Although there was little change in average heterozygosity at allozyme loci in the Domsea line compared to their natural progenitors (Myers et al., 2001a), it is possible that the population has reduced variation at the growth traits under selection. If this outcome is true, there will be lower heterozygosity at marker loci (Lynch and Walsh, 1998). Fewer markers were mapped in the male (31 loci) compared to the female (41 loci), which may be indicative of a decrease in informative markers in the Domsea line generally. Further, there are two factors that may have affected the number of marker-trait associations detected in the male map. Variation in chromosomal locations flanking QTL might have been reduced due to strong artificial selection on growth traits in the Domsea fish (the paternal line), resulting in clustering of QTL and markers that are physically distant from each other. It is also important to point out that male salmonids generally exhibit reduced recombination compared to females (Sakamoto et al., 2000), thus distances between markers and QTL will be reduced in this sex. Reduced recombination in males might have also led to colocalization of QTL that would otherwise be physically distant from each other. It is therefore not possible in this study to resolve which factor, line or sex, has a greater influence on the number of markers linked to QTL, or to the observed colocalization of growth QTL. Increasing marker density for finer scale mapping, and focusing efforts on the female map would address this question in future work.

QTL for growth, length at age and weight at age were detected in both the sire and dam comparisons, indicating that these traits are segregating in both the Satsop and the Domsea populations. The genetic background in which a QTL is detected can affect the percentage of phenotypic variation (PEV) that a QTL explains (Chaib et al., 2006) and whether or not pleiotropy appears to affect a trait (Phillips and McGuigan, 2006). If one trait is segregating in the offspring but the other is not, pleiotropy may fail to be detected. In addition, alleles may vary in their pleiotropic effect (Phillips and McGuigan, 2006) so the identity of alleles present in the parents may impact the ascertainment of pleiotropy at different loci.

Hatch timing in coho salmon is phenotypically correlated with growth at day 213 after fertilization but not at later sample periods. The QTL analysis offers no evidence to suggest that there would be a molecular basis to any phenotypic correlation with this trait. This result was unexpected in light of previous ecological studies that suggest that hatch timing, as a measure of early development, is correlated with growth as alevin and fry (Beacham et al., 1988; Einum and Fleming, 2000; Sundstrom et al., 2005). In an inbred line of rainbow trout, one major QTL for hatch timing was associated with length at the start of exogenous feeding, suggesting a possible genetic correlation between development rate and later growth (Robison et al., 2001). However, undetected hatch-timing QTL of minor effect may be associated with QTL for other growth traits.

The one QTL for hatch timing, associated with marker Omm1241, was detected in the female line. This finding may be indicative of the variation for this trait in the parental lines. In the sire line, the Domsea broodstock, fish have been selected for large size and fast growth to maturity (Myers et al., 2001a) and, simultaneously, for high fecundity (Neely, 2006). There is a trade-off between egg number and egg size and, therefore, eggs from highly fecund females tend to be small (Fleming and Gross, 1990). In a study comparing the Domsea fish to their population of origin, it was observed that the Domsea fish produce smaller eggs than their progenitors (Neely, 2006). In salmonids, small eggs tend to develop more rapidly than do larger eggs (Valdimarsson et al., 2002) and thus selection for fecundity in the Domsea fish may also indirectly select for rapid early development. The dearth of QTL for hatch timing, particularly in the sire line, may indicate that there is little variation for this trait in the Domsea fish, perhaps due to generations of artificial selection, although the trait may still be segregating in the Satsop line. It is also possible that the individuals used in this cross did not capture the true extend of variation for hatch timing in these populations. 
Comparisons with hatch timing QTL in other coho lines would be interesting in resolving this question.

QTL mapped in coho have previously been mapped to homologous linkage groups in other salmon species (Martyniuk et al., 2003; O'Malley et al., 2003; Reid et al., 2005). One QTL for body weight day 293 after fertilization was mapped to RT21 in rainbow trout (Martyniuk et al., 2003); this rainbow trout linkage group is homologous to coho linkage group OKI19 that contains QTL for body weight at all ages measured in this study. In the study of Martyniuk et al. (2003), it was postulated that pleiotropy affected body weight across several months of growth. QTL for body weight at age 1 year were mapped in Atlantic salmon to linkage group AS-18 (Reid et al., 2005) that is homologous to coho linkage group OKI24. Markers on OKI24 do not show any association with QTL for body weight in coho but are associated with other growth QTL (length and growth rate in the second year). In rainbow trout, studies have variously identified QTL of major and minor effect for hatch timing. Nichols et al. (2007) identified six minor QTL for hatch timing, one of which was located on rainbow trout linkage group RT14 (termed OC-14 in Nichols et al., 2007). In this study the QTL for hatch timing was associated with marker Omm1241 that has been mapped to OKI14, the coho linkage group homologous to RT14 (McClelland and Naish, 2008). Robison et al. (2001) identified two major QTL for hatch timing in rainbow trout; each QTL explained around 25\% of the variation seen in the trait. Because different markers were mapped in the various studies, it is not possible to determine if QTL detected in other salmon species map to exactly the same chromosome regions as those in coho. However, presence of QTL for similar phenotypic traits along the same chromosome or chromosome arm may indicate some level of conservation of function across species. Because Atlantic and Pacific species have relatively recently diverged this finding is not particularly surprising. Other recent studies also found conservation of QTL across salmonids including Atlantic and Pacific salmon and Arctic charr (Somorjai et al., 2003; Reid et al., 2005; Moghadam et al., 2007).

Understanding the genetic correlations between traits is important when considering the constraints placed on the evolutionary response of complex traits. It has become increasingly common to use multivariate approaches to the breeder's equation to describe evolution in natural populations (McGuigan, 2006; Garant et al., 2008). In this type of approach, trait interactions are described by the $G$ matrix, a matrix of the genetic variances and covariances between traits (McGuigan, 2006). Although very useful for describing evolution, this multivariate statistical approach assumes that all genetic change is due to additive variance and covariance, and that all underlying QTL are of small effect (Phillips and McGuigan, 2006; Roff, 2007a). QTL analysis, such as the one described here, can offer a more mechanistic understanding of complex traits and genetic correlations between traits, and explain whether the quantitative loci contribute equally to a phenotype. By identifying genomic regions that contribute to the variance of a trait, it becomes possible to further understand the ways in which covariance structures, as described by a $G$ matrix, interact and change over time (Phillips and McGuigan, 2006), which is particularly relevant for future efforts at integrating molecular and multivariate approaches to understanding evolutionary processes (Naish and Hard, 2008).

In this study we located QTL for length, weight, growth rate and hatch timing. This is the first study in salmon to map QTL over as great a range of sampling dates. Presence of multiple QTL mapping to the same location in the genome suggests that there is a genetic basis for the phenotypic correlation observed between many of the studied traits, although it is not possible in this study to distinguish between tightly linked loci and pleiotropy. QTL studies do not have the resolution to determine individual genes, so it is not possible to distinguish pleiotropy from strong linkage disequilibrium between sites (Gardner and Latta, 2007). Therefore, we postulate possible patterns of pleiotropy in this study. Future studies using denser genome maps and sequencing techniques could be used to further distinguish between linkage disequilibrium and pleiotropic effects. This study lays the foundation for future QTL mapping efforts, for location of candidate loci, for more detailed examinations of the genetic basis for phenotypic correlations between growth traits and for exploring the adaptive significance of growth traits in natural populations.

\section{Conflict of interest}

The authors declare no conflict of interest.

\section{Acknowledgements}

We thank D Rose for his assistance with fish rearing and data collection. We also thank the members of the Aquaseed Corporation, suppliers of the Domsea broodstock, and the WDFW employees at the Bingham Creek hatchery. We also thank A Korol for his assistance with the MultiQTL program. This work was funded in part by a grant from the Washington Sea Grant Program, University of Washington to KAN, pursuant to National Oceanic and Atmospheric Administration Award No. NA07OAR4170007, Project No. R/B-41. The views expressed herein are those of the authors and do not necessarily reflect the views of NOAA or any of its subagencies.

\section{References}

Arendt JD (1997). Adaptive intrinsic growth rates: an integration across taxa. $Q$ Rev Biol 72: 149-177.

Beacham TD, Withler RE, Murray CB, Barner LW (1988). Variation in body size, morphology, egg size, and biochemical genetics of pink salmon in British Columbia. Trans Am Fish Soc 117: 109-126.

Beamish RJ, Mahnken C, Neville CM (2004). Evidence that reduced early marine growth is associated with lower marine survival of coho salmon. Trans Am Fish Soc 133: 26-33.

Beckman BR, Larsen DA (1998). Relation of fish size and growth rate to migration of spring chinook salmon smolts. N Am J Fish Manag 18: 537-546.

Biro PA, Abrahams MV, Post JR, Parkinson EA (2006). Behavioral trade-offs between growth and mortality explain evolution of sub-maximal growth rates. J Anim Ecol 75: 1165-1171.

Bradshaw HD, Otto KG, Frewen BE, McKay JK, Schemske DW (1998). Quantitative trait loci affecting differences in floral 
morphology between two species of monkeyflower (Mimulus). Genetics 149: 367-382.

Campbell B, Beckman BR, Fairgrieve WT, Dickey JT, Swanson P (2006). Reproductive investment and growth history in female coho salmon. Trans Am Fish Soc 135: 164-173.

Chaib J, Lecomte L, Buret M, Causse M (2006). Stability over genetic backgrounds, generations and years of quantitative trait locus (QTLs) for organoleptic quality in tomato. Theor Appl Genet 112: 934-944.

Cheverud JM, Rutledge JJ, Atchley WR (1983). Quantitative genetics of development: genetic correlations among agespecific trait values and the evolution of ontogeny. Evolution 37: 895-905.

Churchill GA, Doerge RW (1994). Empirical threshold values for quantitative trait mapping. Genetics 138: 963-971.

Danzmann RG, Gharbi K (2001). Gene mapping in fishes: a means to an end. Genetica 111: 3-23.

Darvasi A (1997). The effect of selective genotyping on QTL mapping accuracy. Mamm Genome 8: 67-68.

Darvasi A, Soller M (1992). Selective genotyping for determination of linkage between a marker locus and a quantitative trait locus. Theor Appl Genet 85: 353-359.

Einum S, Fleming IA (2000). Selection against late emergence and small offspring in Atlantic salmon (Salmo salar). Evolution 54: 628-639.

Einum S, Thorstad EB, Naesje TF (2002). Growth rate correlations across life-stages in female Atlantic salmon. J Fish Biol 60: 780-784.

Erickson DL, Fenster CB, Stenoien HK, Price D (2004). Quantitative trail locus analyses and the study of evolutionary process. Mol Ecol 13: 2505-2522.

Falconer DS, Mackay TFC (1996). Introduction to Quantitative Genetics. Prentice Hall: San Francisco, CA.

Fleming IA, Gross MR (1990). Latitudinal clines: a trade-off between egg number and size in Pacific salmon. Ecology 71: $1-11$.

Garant D, Hadfield JD, Kruuk LEB, Sheldon BC (2008). Stability of genetic variance and covariance for reproductive characters in the face of climate change in a wild bird population. Mol Ecol 17: 179-188.

Gardner KM, Latta RG (2007). Shared quantitative trait loci underlying the genetic correlation between continuous traits. Mol Ecol 16: 4195-4209.

Gregersen F, Haugen TO, Vollestad LA (2008). Contemporary egg size divergence among sympatric grayling demes with common ancestors. Ecol Freshw Fish 17: 110-118.

Heath DD, Fox CW, Heath JW (1999). Maternal effects on offspring size: variation through early development of chinook salmon. Evolution 53: 1605-1611.

Hershberger WK, Myers JM, Iwamoto RN, McAuley WC, Saxton AM (1990). Genetic changes in the growth of coho salmon (Oncorhynchus kisutch) in marine net-pens, produced by ten years of selection. Aquaculture 85: 187-197.

$\mathrm{Hu} \mathrm{Z}, \mathrm{Xu} \mathrm{S}$ (2008). A simple method for calculating the statistical power for detecting a QTL located in a marker interval. Heredity 101: 48-52.

Jensen JOT, Jensen ME (1999). IncubWin: a new Windows 95/98/NT computer program for predicting embryonic stages in Pacific salmon and steelhead trout. Bull Aqua Assoc Can 99: 28-30.

Lander ES, Botstein D (1989). Mapping Mendelian factors underlying quantitative traits using RFLP linkage maps. Genetics 121: 185-199.

Lankford TE, Billerbeck JM, Conover DO (2001). Evolution of intrinsic growth and energy acquisition rates. II. Trade-offs with vulnerability to predation in Menidia menidia. Evolution 55: 1873-1881.

Lynch M, Walsh B (1998). Genetics and Analysis of Quantitative Traits. Sinauer Associates, Inc.: Sunderland, MA.

Mackay TFC (2004). The genetic architecture of quantitative traits: lessons from Drosophila. Curr Opin Genet Dev 14: 253-257.
Mangel M, Stamps J (2001). Trade-offs between growth and mortality and the maintenance of individual variation in growth. Evol Ecol Res 3: 583-593.

Martyniuk CJ, Perry GML, Mogahadam HK, Ferguson MM, Danzmann RG (2003). The genetic architecture of correlations among growth-related traits and male age at maturation in rainbow trout. J Fish Biol 63: 746-764.

McClelland EK, Myers JM, Hard JJ, Park LK, Naish KA (2005). Two generations of outbreeding in coho salmon (Oncorhynchus kisutch): effects on size and growth. Can J Fish Aquat Sci 62: 2538-2547.

McClelland EK, Naish KA (2008). A genetic linkage map for coho salmon (Oncorhynchus kisutch). Anim Genet 39: 169-179.

McGuigan K (2006). Studying phenotypic evolution using multivariate quantitative genetics. Mol Ecol 15: 883-896.

Moghadam HK, Poissant J, Fotherby H, Haidle L, Ferguson MM, Danzmann RG (2007). Quantitative trait loci for body weight, condition factor and age at sexual maturation in Arctic charr (Salvelinus alpinus): comparative analysis with rainbow trout (Oncorhynchus mykiss) and Atlantic salmon (Salmo salar). Mol Gen Genom 277: 647-661.

Myers JM, Heggelund PO, Hudson G, Iwamoto RN (2001a). Genetics and broodstock management of coho salmon. Aquaculture 197: 43-62.

Myers JM, Hershberger WK, Saxton AM, Iwamoto RN (2001b). Estimates of genetic and phenotypic parameters for length and weight of marine net-pen reared coho salmon (Oncorhynchus kisutch Walbaum). Aquac Res 32: 277-285.

Naish KA, Hard JJ (2008). Bridging the gap between the phenotype and the genotype: linking genetic variation, selection and adaptation in fishes. Fish Fish 9: 396-422.

Neely K (2006). Analysis of early development, growth, proximate composition, and digestibility in a domesticated stock of coho salmon (Oncorhynchus kisutch) and its parent stock. MS Thesis, University of Washington.

Neira R, Lhorente JP, Araneda C, Diaz NF, Bustos E, Alert A (2004). Studies on carcass quality traits in two populations of coho salmon (Oncorhynchus kisutch): phenotypic and genetic parameters. Aquaculture 231: 117-131.

Nichols K, Broman KW, Sundin K, Young JM, Wheeler PA, Thorgaard GH (2007). Quantitative trait loci x maternal cytoplasmic environment interaction for development rate in Oncorhynchus mykiss. Genetics 175: 335-347.

Nichols K, Edo AF, Wheeler PA, Thorgaard GH (2008). The genetic basis of smoltification-related traits in Oncorhynchus mykiss. Genetics 179: 1559-1575.

O'Malley KG, Sakamoto T, Danzmann RG, Ferguson MM (2003). Quantitative trait loci for spawning date and body weight in rainbow trout: testing for conserved effects across ancestrally duplicated chromosomes. J Hered 94: 273-284.

Peichel CL, Nereng KS, Ohgi KA, Cole BL, Colosimo PF, Buerkle CA et al. (2001). The genetic architecture of divergence between threespine stickleback species. Nature 414: 901-905.

Perry GML, Audet C, Bernatchez L (2005). Maternal genetic effects on adaptive divergence between anadromous and resident brook charr during early life history. J Evol Biol 18: 1348-1361.

Phillips PC, McGuigan KL (2006). Evolution of genetic variance-covariance structure. In: Fox CW, Wolf JB (eds). Evolutionary Genetics: Concepts and Case Studies. Oxford University Press: Oxford, UK. pp. 608.

Quinn TP (2005). The Behavior and Ecology of Pacific Salmon and Trout. University of Washington Press: Seattle, WA.

Quinn TP, Peterson NP (1996). The influence of habitat complexity and fish size on over-winter survival and growth of individually marked juvenile coho salmon (Oncorhynchus kisutch) in Big Beef Creek, Washington. Can J Fish Aquat Sci 53: 1555-1564.

Reid DP, Szanto A, Glebe B, Danzmann RG, Ferguson MM (2005). QTL for body weight and condition factor in Atlantic 
salmon (Salmo salar): comparative analysis with rainbow trout (Oncorhynchus mykiss) and Arctic charr (Salvelinus alpinus). Heredity 94: 166-172.

Rice WR (1989). Analyzing tables of statistical tests. Evolution 43: 223-225.

Robison BD, Wheeler PA, Sundin K, Sikka P, Thorgaard GH (2001). Composite interval mapping reveals a major locus influencing embryonic development rate in rainbow trout (Oncorhynchus mykiss). J Hered 92: 16-22.

Robison BD, Wheeler PA, Thorgaard GH (1999). Variation in development rate among clonal lines of rainbow trout (Oncorhynchus mykiss). Aquaculture 173: 131-141.

Roff DA (2007a). Contributions of genomics to life-history theory. Nat Rev Genet 8: 116-125.

Roff DA (2007b). A centennial celebration for quantitative genetics. Evolution 61: 1017-1032.

Rogers SM, Bernatchez L (2007). The genetic architecture of ecological speciation and the association with signatures of selection in natural lake whitefish (Coregonus sp. Salmonidae) species pairs. Mol Biol Evol 24: 1423-1428.
Sakamoto T, Danzmann RG, Gharbi K, Howard P, Ozaki A, Khoo SK et al. (2000). A microsatellite linkage map of rainbow trout (Oncorhynchus mykiss) characterized by large sex-specific differences in recombination rates. Genetics 155: 1331-1345.

Shearer KD, Swanson P (2000). The effect of whole body lipid on early sexual maturation of $1+$ age male chinook salmon (Oncorhynchus tshawytscha). Aquaculture 190: 343-367.

Somorjai IML, Danzmann RG, Ferguson MM (2003). Distribution of temperature tolerance quantitative trait loci in Arctic charr (Salvelinus alpinus) and inferred homologies in rainbow trout (Oncorhynchus mykiss). Genetics 165: 1443-1456.

Sundstrom LF, Lohmus M, Devlin RH (2005). Selection on increased intrinsic growth rates in coho salmon, Oncorhynchus kisutch. Evolution 59: 1560-1569.

Valdimarsson SK, Skulason S, Snorrason SS (2002). The relationship between egg size and the rate of early development in Arctic charr, Salvelinus alpinus. Environ Biol Fishes 65: 463-468.

Voorrips RE (2002). MapChart: software for the graphical presentation of linkage maps and QTLs. J Hered 93: 77-78.

Supplementary Information accompanies the paper on Heredity website (http://www.nature.com/hdy) 